\title{
ANÁLISIS NARRATIVO Y GUERRA. \\ La cobertura del diario El País sobre el conflicto de Kosovo
}

CLEMENTE PENALVA

Universidad de Alicante

\section{PALABRAS CLAVE ADICIONALES}

Relaciones Internacionales, Sociología del

Conflicto, Medios de comunicación.
MIGUEL ÁNGEL MATEO

Universidad de Alicante

\section{ADDITIONAL KEYWORDS}

International Relations, Sociology of Conflict, Mass Media.

RESUMEN. Este trabajo es una aproximación a la estructura latente de la cobertura mediática en España de la intervención de la OTAN en Yugoslavia en las fechas en las que se produjo el bombardeo de este país tras el recudrecimiento del conflicto en la provincia de Kosovo. El estudio se basa en el empleo de dos métodos de análisis textuales. Por un lado, se utiliza el análisis semiótico para observar la secuencia narrativa de los acontecimientos (siguiendo a Propp, Levi-Strauss y Greimas) y, por otro, el análisis de contenido que examina las designaciones y atribuciones a los actores implicados en el conflicto, así como su presencia en la secuencia. El corpus textual está formado por las noticias aparecidas en las portadas del diario El País desde unas fechas anteriores al inicio de los bombardeos hasta el 31 de julio de 1999 (un mes después de la firma de los acuerdos entre el ejército yugoslavo y la OTAN para la incorporación de las tropas occidentales en Kosovo). El análisis de los datos muestra una tendencia de los medios a presentar los acontecimientos dentro de una estructura narrativa en la cual se pueden determinar los actores, la secuencia de los relatos y las entidades contracturales y sancionadoras de la realización del héroe de cuento, así como el sistema de oposiciones binarias que contribuyen al desarrollo de la historia.

Revista Internacional de Sociología (RIS)

Tercera Época, ${ }^{\circ} 26$, Mayo-Agosto, 2000, pp. 187-210. 


\section{CUESTIONES TEÓRICAS Y METODOLÓGICAS}

Desde hace algunas décadas los estudios sobre comunicación de masas han asumido la importancia de las pautas culturales a la hora de elaborar los contenidos informativos, así como la recepción de los mismos. Se descubre que los procesos de seleccionar y excluir temáticas, de otorgar mayor importancia a ciertos acontecimientos, y la tendencia a la dramatización, son muestras del paralelismo existente entre las historias narradas y los mitos culturales (Carey, 1992; Schudson, 1989; Tuchman, 1983; Fiske y Hartley, 1978). La eficacia de las estructuras narrativas y simbólicas radica en su función de instrumento para introducir los valores y normas que sirven de base para la formación de las creencias y para la construcción de la realidad.

El análisis narrativo permite la elaboración de modelos: de personajes narrativos, de tramas y de oposiciones. No sirve solamente para ayudar a acceder al significado contenido en el esquema narrativo, sino también a detectar las implicaciones en cuanto a los efectos ideológicos (Hanse et al., 1998). También la narrativa se puede entender como una forma de organizar y conocer el mundo. Así, con relación a la audiencia, la narrativa coincide con los llamados «esquemas» (Fiske y Taylor, 1991) donde el receptor organiza sus experiencias dentro de unas estructuras cognitivas. En la recepción de los mensajes mediáticos el esquema se compone de una serie de «expectativas» acerca de lo que va ocurriendo: caracteres, temáticas, acciones y finales. Cuando se encuentra consistencia entre la nueva experiencia mediática y las expectativas, el esquema se refuerza. El funcionamiento de estos esquemas puede explicar el proceso de internalizalización de modelos de representación de la violencia por parte de la audiencia (Cerulo, 1998).

Este artículo, siguiendo los desarrollos en torno al análisis narrativo que parte de Propp (1977), perfeccionado por Levi-Strauss (1961) y Greimas (1980), trata de identificar los roles, funciones y oposiciones binarias que proporcionan el armazón del texto (las noticias que en una disposición secuencial construyen la trama).

La primera formulación parte de Propp en su estudio sobre las regularidades narrativas en el cuento. Su método se basa en señalar el desarrollo secuencial de la trama narrativa en la cual se han de observar los roles (héroe, villano, destinador, hechicero, ayudante, falso héroe) que son desempeñados por los personajes; $y$ las funciones, entendidas como actos de los diferentes personajes, que hacen desarrollarse la trama (hasta un total de 31). Si Propp se centra en el proceso (eje sintagmático del relato) donde las funciones van desde la preparación del héroe hasta el reconocimiento público una vez superadas las pruebas, Levi-Strauss descubre el sistema. Su aproximación paradigmática al relato muestra cómo los patrones de oposiciones que existen en la narración contribuyen al desarrollo de la historia (salida-retorno, creación de la carencia-liquidación de la carencia, constitución de lo prohibido-ruptura de lo prohibido). 
Para Greimas, a mitad de camino entre los dos anteriores, el análisis se ha de centrar tanto en la acción - en las relaciones entre personajes-, como en los actantes (definidos por sus acciones y sus relaciones con otros personajes, a través de oposiciones tipo destinador/destinatario o sujeto/objeto). Esto supone que dos roles pueden ser representados por un mismo personaje y que los propios personajes se realizan en la historia a través de las transformaciones que operan a lo largo de la trama narrativa. Además, y esto se debe a Levi-Strauss, permite el análisis a partir de las discontinuidades: los emparejamientos narrativos no se han de hacer por su continuidad textual, sino que un enunciado narrativo remite a un enunciado narrativo inverso planteado con anterioridad. Esto es sólo reconocible mediante una lectura hacia atrás. Observamos que este esquema es el más idóneo para el análisis del género noticias sobre un mismo tema, en este caso la cobertura del conflicto en Kosovo. Como no existe enlace directo entre las noticias, más aún entre los titulares cuya disposición se asemeja a pinceladas dispuestas sobre el plano sintagmático, la lectura hacia atrás es la que permite formar una composición global.

\section{Muestra. Diario y fragmentos seleccionados}

El corpus textual sobre el que se ha realizado el análisis está formado por el conjunto de informaciones (escritas y gráficas) que sobre el asunto (el conflicto de Kosovo) fueron apareciendo en las portadas del diario El País desde el 11 de marzo de 1999 (dos semanas antes del inicio de las acciones bélicas de la OTAN), hasta el 30 de julio del mismo año. La muestra, por lo tanto, es exhaustiva y se centra (en lo relativo al texto) sobre dos recursos de expresión (portada y titular) que los diarios emplean para enfatizar determinados hechos y como función de

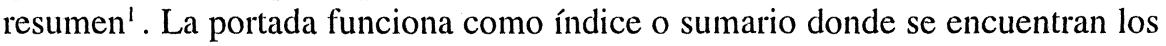
principales temas para el lector y como indicador de selección institucional de lo relevante para el investigador. El titular junto con el resumen expresan los principales temas del hecho, pero también se conoce la tendencia hacia el impacto, la sensación, al intentar reducir toda la información a una frase y captar la atención del lector. La primera "imagen" que se recibe en el titular es, muchas veces, la que permanece incluso tras la lectura del texto completo. Por otro lado, sabemos

\footnotetext{
' Tanto el titular como la portada (así como el tipo de letra y su tamaño) son recursos expresivos del periodista en la superficie redaccional, ya que no puede, al contrario que en los mensajes icónicos (fotografías, imágenes de TV), producir sustancias expresivas donde participe el propio objeto de referencia (Arias, 1986). Así, estos recursos sirven para enfatizar algún aspecto del mensaje, con una función conativa sobre el lector. El sensacionalismo juega principalemente con estos recursos.
} 
que el encabezamiento cumple algunas funciones en torno a la comprensión de las noticias en cuanto a los procesos de cognición (memoria y reconocimiento). El lector del periódico utiliza determinadas estrategias siguiendo la estructura del discurso periodístico y viceversa, las estructuras se adaptan a las estrategias de lectura (Van Dijk, 1990). Dadas estas funciones consideramos que el corpus textual permite acceder a la secuencia de los acontecimientos más importantes que la institución periodística ha seleccionado.

Con respecto a la decisión de elegir un medio específico (El País) obedece a la idoneidad del muestreo de casos críticos (aquél que puede servir de referencia lógica para el resto de la población o parte de ella, en relación al tema de estudio [.......] los muestreos de casos críticos hacen posibles generalizaciones lógicas derivadas del peso de la evidencia que puede llegar a producir incluso un solo caso, González Río, 1997: 118). Las dimensiones claves que otorgan la calidad de «caso crítico» al diario El País vienen determinadas por su papel triple de periódico progresista (en contraste con otros medios y actualmente portavoz mediático de la oposición parlamentaria al gobierno); de referencia dominante (Imbert y Vidal-Beneyto, 1986) y constructor de la realidad (Ibáñez, 1994) en España desde la transición; y de liderazgo en cuanto a su extensión en la audiencia. En principio, se selecciona un periódico de izquierdas y opositor a partir del presupuesto de que el pacifismo tradicional de la socialdemocracia produce un discurso menos belicista que otros medios más conservadores y progubernamentales.

Los autores son conscientes de la limitación en cuanto al impacto sobre la audiencia de la prensa con respecto a la televisión, toda vez que la cobertura de este medio sobre el conflicto específico que tratamos ha sido muy extensa sobre el recurso expresivo de la imagen. No obstante, la forma escrita del periódico ${ }^{2}$ otorga ciertas ventajas. En primer lugar, la prensa escrita tiene mayor incidencia en la formación de una opinión pública más consistente y consciente. Su papel conformador de opinión pública informada conserva el carácter clásico de opinión razonada y crítica. En segundo lugar, las características del soporte garantizan su independencia en cuanto al tiempo y al espacio, aspecto que permite una recepción del mensaje que viene determinada por el propio receptor (lectura rápida o pausada e, incluso, relectura). En tercer lugar, los diarios sirven de referencia para los segmentos socioculturales más elevados y, en gran medida, forman su opinión. Este hecho comporta una notable trascendencia sociológica: estos estratos sociales son la fuente de la toma de decisiones, marcan modelos

\footnotetext{
${ }^{2}$ Las implicaciones en torno a la forma y recepción de los mensajes determinadas por la tecnología del medio están basadas en Martín Serrano (1986), McLuhan (1989) y Sartori (1998).
} 
de conducta y estructuran el liderazgo (político y de opinión). Desde el punto de vista metodológico, la elección del medio también obedece a unas razones técnicas: la prensa escrita permite al investigador un mayor control sobre el significado porque se opera sobre datos verbales y no sobre imágenes. La prensa otorga mayores facilidades para la codificación y la determinación de las unidades de análisis. El tratamiento de toda la información es uniforme, ya que todas las unidades de análisis se sitúan al mismo nivel, algo imposible si se trabaja con signos no verbales (planos, gestos, escena, etc.).

La primera información que ofrece el análisis de los datos es la amplia cobertura del conflicto. Desde el 11 de marzo hasta el 30 de julio de 1999, desde el anuncio de la decisión firme de bombardear Yugoslavia hasta el despliegue de las fuerzas terrestes por la provincia de Kosovo, 161 noticias sobre el tema objeto de estudio aparecieron en las portadas del diario El País. Una presencia continuada en primera página con una significativa presencia de expresión icónica mediante fotografías. Esta presencia solamente fue interrumpida una fecha desde el inicio de los bombardeos hasta los primeros días del despliegue terreste aliado.

\section{Narrativa y secuencia temporal de las noticias}

La intención de este trabajo difiere en parte de la mayoría de estudios sobre las noticias internacionales que han estudiado la cobertura a lo largo del tiempo de un determinado acontecimiento, como son las crisis políticas o económicas de un determinado país. El principal hallazgo de estos trabajos es que las noticias internacionales no tienen estructura, en el sentido de que las informaciones son puntuales, se rigen por el principio de impacto y carecen de antecedentes y consecuencias de los hechos relatados (Galtung y Ruge, 1965; Rosengren, 1970; Rosenblum, 1979; Hedman, 1981), con importantes consecuencias en torno al conocimiento de la audiencia (Hurwitz y Perffley, 1990). Sin embargo, este estudio trata de detectar la estructura narrativa latente, situando en un segundo plano la cantidad de la información presentada, y su estructura en cuanto a la relación entre hechos narrados y referente; centrándose, más bien, en la forma bajo la cual se ha mostrado a la audiencia bajo el género informativo de la noticia (Katz, 1992; Glasgow University Media Group, 1982) el discurso sobre la guerra de Kosovo.

Este enfoque no es nuevo; se ha estudiado la tendencia a la dramatización en lo que se refiere a la manera de presentar los relatos periodísticos sobre determi-

\footnotetext{
${ }^{3}$ El proceso de clasificación de las unidades en el análisis de contenido de la cobertura ha sido efectuado mediante el programa de análisis de textos TEXTPACK; una vez obtenida la matriz de datos, el análisis estadístico se ha realizado con el programa SPSS
} 
nados acontecimientos, si bien tomando la noticia como unidad de análisis y no toda la cobertura. Lo que se pretende aquí es observar la estructura narrativa que conforma la disposición episódica y continua de las noticias aparecidas durante 6 meses sobre la crisis internacional de Kosovo. La información aparecida durante este período se asume como diario o «itinerario de una campaña». Es por ello que el análisis, a pesar de la segmentación inherente a la presentación diaria del género noticias, necesita concebir el total de la información como un solo texto dotado de autonomía y con una orientación, como objeto semiótico dotado de coherencia interna y como proceso o discurso (Lozano et al., 1986: 15-53; Floch, 1993) ${ }^{4}$.

\section{APROXIMACIÓN SINTAGMÁTICA}

\section{Análisis semiótico}

Un aspecto esencial dentro del esquema de Greimas es la presentación general del esquema narrativo basado en cuatro elementos:

Contrato: a partir de un sistema de valores aparece la proposición por parte del destinador (depositario de estos valores) de un programa a realizar por el sujeto.

Competencia: adquisición por parte del sujeto de la aptitud para realizar la tarea encomendada. Prueba cualificante (en términos de Propp).

Performance: realización del programa. Prueba decisiva (Propp).

Sanción: comparación del contrato planteado con las acciones del sujeto y reconocimiento por parte del destinador. Prueba glorificante (Propp) ${ }^{5}$.

\footnotetext{
${ }^{4}$ Un pormenorizado análisis revelaría en la secuencia de noticias que cubren la guerra cómo se producen las diversas formas de coherencia textual (cohesión, coherencia global y pragmática y coherencia interna).

${ }^{5}$ Se ha de hacer notar la simetría que presentan estos cuatro elementos. Contrato-Sanción: mientras en el primero el destinador exige el cumplimiento de un programa a realizar por el destinatario, una vez completado el mismo es el destinatario el que puede exigir el reconocimiento; mientras en el contrato el sujeto decide si acepta o no la misión, en la sanción el destinatario convertido en este momento en juez decide si glorifica o no al sujeto. Competencia-Performance: la superación de pruebas cualificantes va a permitir al sujeto realizar su misión; por otro lado, la realización de la «prueba decisiva» presupone la competencia del héroe para llevarla a cabo.
} 
Tabla 1.

Esquema narrativo de la cobertura de la guerra en Kosovo

\begin{tabular}{|c|c|c|c|}
\hline Contrato & Competencia & Performance & Sanción \\
\hline $\begin{array}{l}\text { Opinión pública, ONG’s, } \\
\text { establecen las bases del } \\
\text { contrato: intervención sin } \\
\text { víctimas civiles ni propias } \\
\text { para acabar con la } \\
\text { represión en Kosovo }\end{array}$ & $\begin{array}{l}\text { Pérdidas y ganancias de } \\
\text { competencia: "pruebas } \\
\text { cualificantes" } \\
\text { Pérdidas: incapacidad } \\
\text { diplomacia; daños } \\
\text { colaterales, incapacidad de } \\
\text { los ayudantes (UCK, Rusia, } \\
\text { parlamentarismo europeo), } \\
\text { Improvisación campos de } \\
\text { refugiados, desorganización } \\
\text { del retorno de refugiados, } \\
\text { secuestro de militares USA, } \\
\text { caída del avión espía. } \\
\text { Bombardeo por error de la } \\
\text { embajada China Venganza } \\
\text { delos albaneses sobre los } \\
\text { serbios de Kosovo. } \\
\text { Ganancias: consenso de } \\
\text { las democracias mundiales. } \\
\text { Incorporación de tecnología } \\
\text { para el bombardeo aéreo } \\
\text { sin víctimas propias. }\end{array}$ & $\begin{array}{l}\text { Prueba decisiva } \\
\text { Presión militar y } \\
\text { económica sobre el } \\
\text { estado yugoslavo } \\
\text { para la consecución } \\
\text { de un acuerdo. } \\
\text { Negociación entre } \\
\text { generales ante el } \\
\text { ultimátum de la } \\
\text { OTAN. } \\
\text { Introducción de } \\
\text { tropas en Kosovo. } \\
\text { Capitulación de } \\
\text { Milosevic. }\end{array}$ & $\begin{array}{l}\text { Aclamación de las } \\
\text { tropas aliadas en la } \\
\text { entrada a Kosovo. } \\
\text { Resurgimiento de la } \\
\text { oposición yugoslava a } \\
\text { Milosevic. Ganancia } \\
\text { de un nuevo aliado } \\
\text { (Rusia). Retorno de } \\
\text { refugiados. } \\
\text { Liberación de presos } \\
\text { torturados. } \\
\text { Autorización del } \\
\text { Consejo de Seguridad } \\
\text { de la ONU al plan de } \\
\text { paz. } \\
\text { Anuncio de plan } \\
\text { Marshall para los } \\
\text { Balcanes. } \\
\text { El Tribunal de la Haya } \\
\text { inicia el proceso } \\
\text { contra Milosevic (la } \\
\text { OTAN aplaude la } \\
\text { decisión). } \\
\text { Pruebas para el } \\
\text { descubrimiento de la } \\
\text { verdad (fosas). }\end{array}$ \\
\hline
\end{tabular}

Más adelante profundizaremos sobre los actores/personajes de la estructura narrativa, pero como avance para la comprensión de la tabla 1 señalaremos las siguientes correspondencias:

Destinador: la humanidad (una especie de sociedad civil mundial y sus representantes públicos y mediáticos).

Receptor o destinatario: la OTAN, los EE.UU., los líderes occidentales reciben el encargo de actuar para la consecución de los objetivos planteados.

Sujeto: la OTAN, al mismo tiempo que es receptor, es el héroe que se realiza con la acción.

Objeto: la población albanokosovar, arrancada de su lugar de origen por las acciones de la población serbia. 
Oponente o anti-sujeto, en forma de villano: Milosevic como encarnación de la dictadura férrea frente a las democracias occidentales, con un plan premeditado de eliminación de la población albanokosovar

Ayudante: principalmente Rusia, con un papel ambiguo entre oponente y ayudante; la UE con su falta de decisión y apocada ante un conflicto que está muy cerca de sus fronteras.

\section{Los actantes/personajes y sus relaciones}

\section{Destinador/destinatario (sender/receiver)}

En todo relato se plantea por una autoridad superior (instancia que representa los valores, el bien/el mal) el encargo al héroe de una determinada misión. La autoridad es el destinador y el héroe es el destinatario. Tras un período en el cual el sujeto debate interiormente si aceptar o no el reto, el destinador acepta las condiciones del contrato. El destinatario aquí es la OTAN, sujeto que se realiza, ya que operan transformaciones también en su interior como veremos más adelante. Si bien la identificación del destinatario con la OTAN (o personificada en un grupo de líderes en forma más o menos colegiada bajo una cabeza destacada, Clinton) es bastante clara, parece más difusa la definición del destinador. Si la razón de la guerra es ante todo moral y humanitaria (donde un objeto - los albanokosovares- es expulsado de su tierra y se convierte en refugiado) el destinador ha de ser «la humanidad» (respeto a los derechos humanos y autonomía de un pueblo) encarnada por la opinión pública. Los medios de comunicación han apelado desde el inicio de la desintegración de la antigua Yugoslavia a principios de los 90 a la «responsabilidad» de los países occidentales frente a la barbarie del genocidio. El par humanitarismo-opinión pública (ONG's-medios), de hecho, ha sido fundamental a la hora de percibir las intervenciones (armadas o no) de Occidente en multitud de conflictos inter-étnicos en el mundo (Fisas, 1998).

Las reflexiones sobre la implicación del sujeto, sobre su implicación o no en el conflicto, se puede observar a partir de la lógica que envuelve el debate sobre la intervención. Este puede ser representado a partir del cuadrado semiótico (cuadro 2), siendo la categoría básica la de la responsabilidad, o en términos semióticos el deber hacer ${ }^{6}$. En este cuadrado se presentan las posibles alternativas ante el establecimiento del contrato: puesta en funcionamiento de las condiciones para una liberación - más tarde se incorpora el regreso- de los habitantes albanokosovares, así como la interrupción del programa de limpieza étnica serbio.

"A partir de las modalidades deónticas (Abril, 1994: 461) de Greimas y Courtés. 


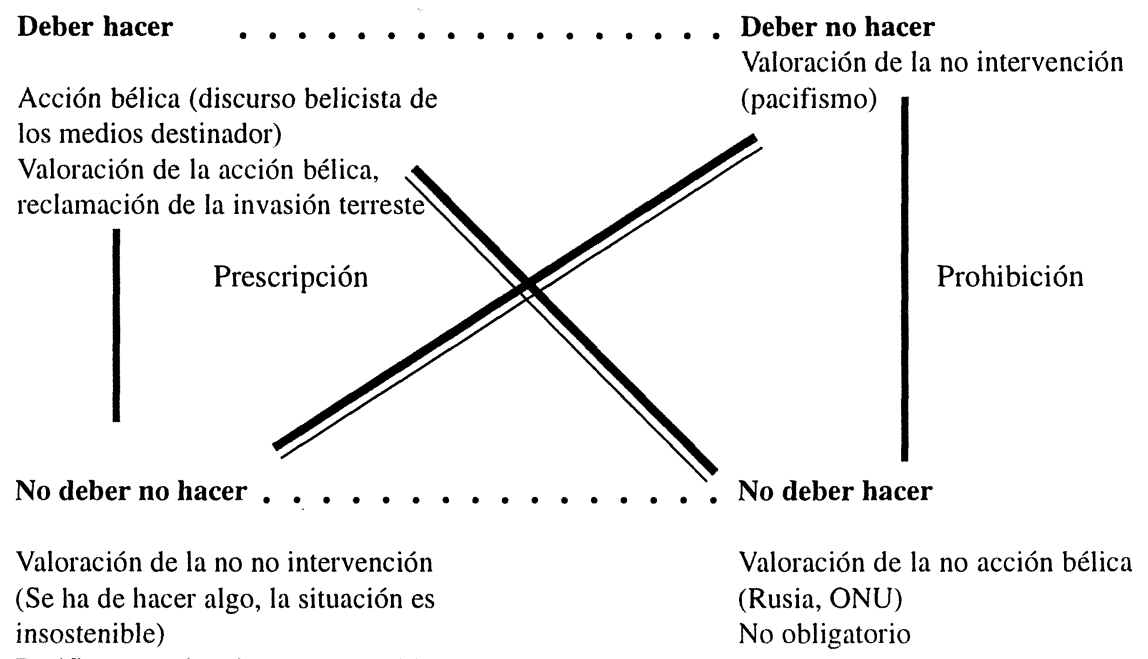

Pacifismo moderado o reconvertido

Cohn-Benedit

Autorización

Permisividad

Facultatividad

- . Relación de contrariedad

1 Relación de contradicción

Relación de complementariedad

Los diferentes discursos y alternativas a la intervención quedan así resumidas, presentando las relaciones de contrariedad, complementariedad y contradicción ${ }^{7}$.

1. Deber hacer. Desde el recudrecimiento de la guerra en Bosnia los representantes de la opinión pública, los medios, han ido reclamando a diferentes organizaciones internacionales (UE, ONU, OTAN) acciones destinadas a interrumpir el conflicto a través de diferentes medidas: mediación, diplomacia, san-

\footnotetext{
${ }^{7}$ El cuadrado semiótico se introduce aquí solamente de modo aproximativo con el fin de presentar una taxonomía de los diferentes discursos sobre la guerra. Su exposición aquí es meramente ilustrativa y se reconoce que una profundización mediante este instrumento sobre el mismo objeto (discursos sobre Kosovo) merece, cuando menos, un ensayo expresamente redactado para este fin.
} 
ciones, embargos, etc., hasta la intervención armada ${ }^{8}$. Sobre el conflicto en Kosovo la consonancia entre el discurso mediático y el estadounidense ha sido patente: no vale con las soluciones diplomáticas ni con las medidas de embargo económico y militar. Se exige la implicación bajo los principios inviolables de la dignidad humana y los derechos humanos para detener el plan de limpieza étnica serbio. La vía definitiva para acabar con los desmanes serbios sobre la población albanokosovar es la intervención militar. Subyace algo más: la responsabilidad del mundo «civilizado» sobre los atentados contra los derechos humanos en cualquier lugar del mundo. Por otro lado, la coincidencia mediático-militar aparece claramente expresada en el desarrollo del discurso belicista: tecnología militar (bombas inteligentes), la estrategia (gráficos sobre las campañas, incursiones aéreas, posiciones en el frente), el fetichismo de las armas, etc.

2. Deber no hacer. El discurso parte de la base de un principio superior que es el respeto de la vida humana y para ello se aboga por la utilización de métodos no violentos para la resolución de conflictos. Se valora la «no intervención» (armada) tanto desde el punto de vista moral como pragmático (la violencia siempre engendra violencia). Así, frente a la «guerra justa» utilizada como argumento en 1 , se aboga por la no violencia. El sentido de la responsabilidad considerado de manera horizontal (multicultural) y no jerárquico como en 1 (civilizaciónbarbarie) introduce la prohibición frente a la prescripción del uso de la violencia.

3. No deber no hacer. Ciertamente se reconocen los peligros y consecuencias negativas de la acción bélica (sufrimiento tanto de la población civil como de la militar, sobre todo de la población yugoslava), pero el sentido de la responsabilidad apunta hacia la imposibilidad de «no hacer nada» ante la barbarie. En este discurso no se magnifica la capacidad militar ni la estrategia, sino que se mueve exclusivamente sobre el terreno de lo ético, haciendo pues abstracción del instrumento bélico y de las víctimas. El fenómeno del eufemismo aplicado a la descripción de hechos militares ha debido ser inventado aquí: «víctimas colaterales», «fuego amigo». Los ejemplos ilustrativos pueden estar en el pacifismo reconvertido (Cohn-Bendith), parte de la izquierda europea y cierta intelectualidad. Frente al pacifismo radical que representa la prohibición, el pacifismo reconvertido plantea un discurso permisivo. En cuanto a su relación con 1 y 2, no se llega a valorar la acción bélica, pero se valora la no no intervención en contradicción con 2 .

\footnotetext{
${ }^{8}$ El discurso contiene una lógica de escalamiento (de menor a mayor) en cuanto a la intensidad de la presión, que se explicita en las posibles acciones hasta la consecución del fin propuesto: mediación, embargo militar, embargo económico, incremento gradual en el uso de la fuerza militar, aunque existen pruebas del falseamiento en cuanto al agotamiento real de las primeras medidas en distintas guerras (un ejemplo la guerra de las Malvinas) (Glasgow University Media Group, 1985).
} 
4. No deber hacer. El más problemático pues, representa lo facultativo (si el 3 es no prohibido, el 4 es no obligatorio). La ONU podría presentar este discurso, ya que el no consenso entre el Consejo de Seguridad (oposición China y Rusa) tendría que producir la imposible (por la oposición del resto del Consejo) sanción a un guerra ilegal por el hecho de injerir sobre asuntos internos de un país en forma bélica. La posición de China no cabe dentro de este apartado, pero sí algunos elementos de la ambivalente posición Rusa. El resultado, no obstante, y de ahí la complementariedad con 2 , es la oposición a la acción bélica aunque no con el componente moral del pacifismo: no es obligatorio el uso de la fuerza, se han de tomar cualquier otro tipo de medidas.

\section{Objeto/Sujeto (sujetos)}

Para Greimas, se ha de hacer una distinción entre los sujetos de estado y los sujetos de hacer. Los sujetos de estado lo son en razón de sus junciones con los objetos y son los depositarios de los valores. Los sujetos de hacer son sujetos actuantes que por operar esas uniones transforman a los sujetos de estado. En la historia narrada en los medios, los albanokosovares (salvo algunas menciones a sus representantes, o al grupo armado UCK) aparecen claramente definidos como sujetos de estado (la imagen recurrente de los refugiados) ligados a la tierra. La transformación que se opera es: unidos a la tierra, desunidos por la acción de un sujeto de hacer (Serbia, Yugoslavia, Milosevic), son devueltos a su estado originario por otro sujeto de hacer (la OTAN).

\section{Sujeto y oponente. El desdoblamiento del relato y los itinerarios narrativos}

Los itinerarios narrativos son introducidos por Greimas para aludir a la complejidad del relato, al desdoblamiento donde se narran las pruebas a las que son sometidos tanto el sujeto como el antisujeto. Desde el punto de vista formal estos dos relatos no se distinguen uno de otro, al cruzarse y entreverarse, salvo por su coloración moral diferente, positiva o negativa. Estos itinerarios narrativos que se desarrollan en direcciones opuestas acaban encontrándose en forma de polémica o transacción (combate o intercambio). A continuación pasamos a describir los itinerarios narrativos de ambos sujetos (OTAN, Milosevic) y comprobar sus puntos de cruce.

a) Actualización de la OTAN. Desde la caída del muro, las competencias de la Alianza quedan cuestionadas (del papel bien definido durante la guerra fría de contención de la amenaza comunista a su indefinición). La guerra de Kosovo sirve de actualización porque presenta nuevos retos. Obviamente, el cambio de orientación lleva preparándose desde la caída del muro en Europa, y ha dispuesto de numerosas pruebas en el conflicto yugoslavo en la presente década (la intervención sobre Bosnia que permitió la ofensiva croata-musulmana como pre- 
ludio de los acuerdos de Dayton).

Si la guerra del Golfo fue el inicio del nuevo papel de los EEUU como cabeza de una alianza mundial, la de Yugoslavia ha supuesto su realización como potencia hegemónica de una forma más cristalizada (en la OTAN), mostrando la pérdida de competencia de sus aliados europeos, tras una prueba realizada sobre suelo europeo. Los medios se han esforzado en presentar la ofensiva como una acción conjunta de una Alianza con una dirección más o menos colegiada con un liderazgo estadounidense (Clinton) apoyado con diferentes figuras europeas relevantes: Schröder, Blair, Solana, Jospin.

b) La consecución de la limpieza étnica de Milosevic. Milosevic representa la intolerancia y el deseo imperialista de mantener el antiguo Estado yugoslavo bajo el liderazgo de la gran Serbia. Se parte de un importante background suministrado por los medios desde el inicio de la década, en el cual se ha hecho más énfasis en las atrocidades serbias (como paradigma el asedio a Sarajevo) que las del resto de partes implicadas en el conflicto. Así, queda perfilado claramente el itinerario: tras las pérdidas de diferentes territorios de la antigua Yugoslavia, Milosevic se esfuerza en mantener una Serbia limpia étnicamente y conservar un territorio de gran importancia simbólica porque representa las raíces históricas del nacionalismo serbio. Para ello no es suficiente con la represión y la supresión de la autonomía política de Kosovo dentro del estado yugoslavo, sino que se han de poner las condiciones para la huida hacia el exterior de los habitantes de origen albanés en la provincia.

Milosevic también presenta una realización, en este caso como antihéroe. Mediante un contrato, perverso, de complenitud de la pureza étnica serbia va perdiendo a lo largo del texto todas sus pruebas de competencia. Al cruzarse su realización con la del héroe, las pérdidas de competencia se van convirtiendo en ganancias para los aliados. Visto en negativo también puede observarse su paso por las «etapas» de realización efectiva de un proyecto. La (amenazante) alianza paneslava con Rusia y la huida de albanokosovares de la provincia, la lucha contra la guerrilla del ELK y el apoyo unánime de la sociedad serbia constituyen pruebas de competencia en detrimento de la realización del héroe. La prueba definitiva no es superada, al ser obligado a retirar sus tropas de la provincia de Kosovo; y la sanción — negativa - queda constituida por el abandono y la rendición de cuentas ante la sociedad civil yugoslava".

\footnotetext{
'Se ha de observar la diferente manera de designar a los diferentes grupos políticos existentes en Yugoslavia: mientras durante las primeras fases (fuera de los titulares) de la guerra se utiliza el término serbio, una vez acabada la ofensiva emerge la oposición «yugoslava» convertida en este momento en destinador y que sanciona de manera desaprobatoria las acciones del antihéroe.
} 
La personificación del mal en una sola persona (Milosevic), limita la caracterización, no obstante, del antihéroe en cuanto a la ausencia de ayudantes. Su segundo critica abiertamente sus acciones; Rugova acaba siendo recibido en Occidente tras la aparición pública — descrita como forzada - pidiendo el cese de los bombardeos, lo que hace que pase de ayudante oponente a ayudante del héroe (de Rugova, no obstante, se proyecta su condición de líder elegido democráticamente del pueblo kosovar; y no su naturaleza pacifista); su hermano mayor - Yeltsin, Rusia - que comienza amenazando con su intervención armada para defenderle, acaba siendo un firme aliado de Occidente ${ }^{10}$; el resto de la familia eslavo-ortodoxa sigue unas pautas parecidas al abandonar su filiación para engrosar las filas aliadas; la república de Montenegro, parte del todo yugoslavo es mantenida firme bajo las amenazas de Belgrado.

\section{ANÁLISIS DE CONTENIDO}

A continuación se presentan los resultados obtenidos del análisis de contenido sobre los 161 titulares de la muestra. Sobre el eje temporal se establecen las siguientes categorías: violencia normal, violencia desviada, daños colaterales, prueba definitiva, prueba glorificante ${ }^{11}$.

\section{Sistema de categorías}

1. Violencia normal (ganancia de competencia). Se trata de la violencia física «legítima» no reprobada por los medios, propia de la dinámica bélica, donde no aparece mención ni a las víctimas, ni a los efectos no estratégicos de los bombardeos. Coincide totalmente con la de la OTAN sobre objetivos militares y económicos yugoslavos.

\footnotetext{
${ }^{10}$ A cambio de «un puñado de dólares», con lo cual no pierde totalmente su condición villana, sino que la refuerza, pues abandona por razones materiales un contrato fundamentado axiológicamente; y además, rompe el compromiso con Occidente al tomar el aeropuerto de Pristina.

"La distinción entre violencia normal y violencia desviada aparece cuando se observa el componente moral asociado a cada una de ellas. Cuando se llama la atención del lector sobre las víctimas, mostrando el sufrimiento, nos encontramos con la violencia desviada. Todo lo contrario ocurre cuando la violencia es considerada normal aquí se dirige la percepción de la audiencia sobre el agente de la agresión. Aunque los daños colaterales fijan la atención sobre las víctimas, no son considerados como violencia desviada, ya que se justifican a partir del término «error» presente en las crónicas, en contraste con la ausencia de justificación de la violencia yugoslava, que más bien aparece como premeditada.
} 
2. Violencia desviada (pérdida de competencia). Se trata de la violencia física de orden patológico, no justificada, y donde aparecen tanto las víctimas como las consecuencias de la acción violenta. Es la que lleva a cabo el «programa» de limpieza étnica aplicado por el régimen yugoslavo; aparece expresada principalmente bajo la forma de expresión gráfica a través de la fotografía (huida de los refugiados, campos de concentración, acciones de las milicias serbias sobre los albanokosovares).

3. Daños colaterales y desatención refugiados (pérdida de competencia). Con este nombre se asocian los «errores» cometidos por las acciones militares de la alianza, los efectos sobre la población civil y los fallos en la atención de los refugiados (falta de previsión en los campos, falta de fondos y fallos en la organización del retorno).

4. Prueba decisiva (performance). Tras la adquisición de una competencia a través de las pruebas cualificantes $(1,2 \text { y } 3)^{12}$, el sujeto es capaz de realizar una serie de pruebas decisivas. Aquí entran los éxitos diplomáticos (consecución de la mediación rusa) y la capitulación serbia (aceptación de las condiciones aliadas), el despliegue terrestre, el retorno de los refugiados y la liberación de presos de las cárceles serbias en Kosovo.

5. Prueba glorificante (sanción). Va asociada al reconocimiento del destinador de las acciones llevadas a cabo por el sujeto. Está cargada de valores por su referencia al contrato: aclamación de las tropas aliadas en la entrada a Kosovo (liberación), el resurgimiento de la oposición yugoslava a Milosevic (democracia), el proceso del Tribunal de la Haya contra Milosevic (justicia), el descubrimiento de fosas (pruebas para el reconocimiento de la verdad), anuncio de plan Marshall para los Balcanes (solidaridad), la autorización del Consejo de Seguridad de la ONU para el plan de paz y la ganancia de un nuevo aliado, Rusia (universalismo).

En el gráfico se puede observar la secuencia en el tiempo de los acontecimientos que sobre la guerra han sido seleccionados por el medio. Los antecedentes de la guerra (muy cargados de violencia desviada) conducen al inicio de la ofensiva aliada, la cual solamente se interrumpe con la entrada de «daños colaterales» hasta la capitulación serbia (prueba decisiva). Paralelamente, la violencia «desviada» sobre los refugiados llena los huecos de la violencia normal. Cumple pues las funciones de justificación de la «violencia normal» y de mitigación de los efectos no deseados; así como de recordatorio del compromiso adquirido

\footnotetext{
${ }^{12}$ En la estructura del cuento siempre aparece un otro que contraría las acciones del héroe: el ayudante y el oponente. Dichos personajes representan bajo la forma de actores, aumentos o pérdidas de competencia: así el incremento de competencia del oponente (limpieza étnica, expulsión albanokosovares) se puede entender como pérdida de competencia del sujeto.
} 
Gráfico 1.

Secuencia temporal de noticias (agrupadas según categorías)

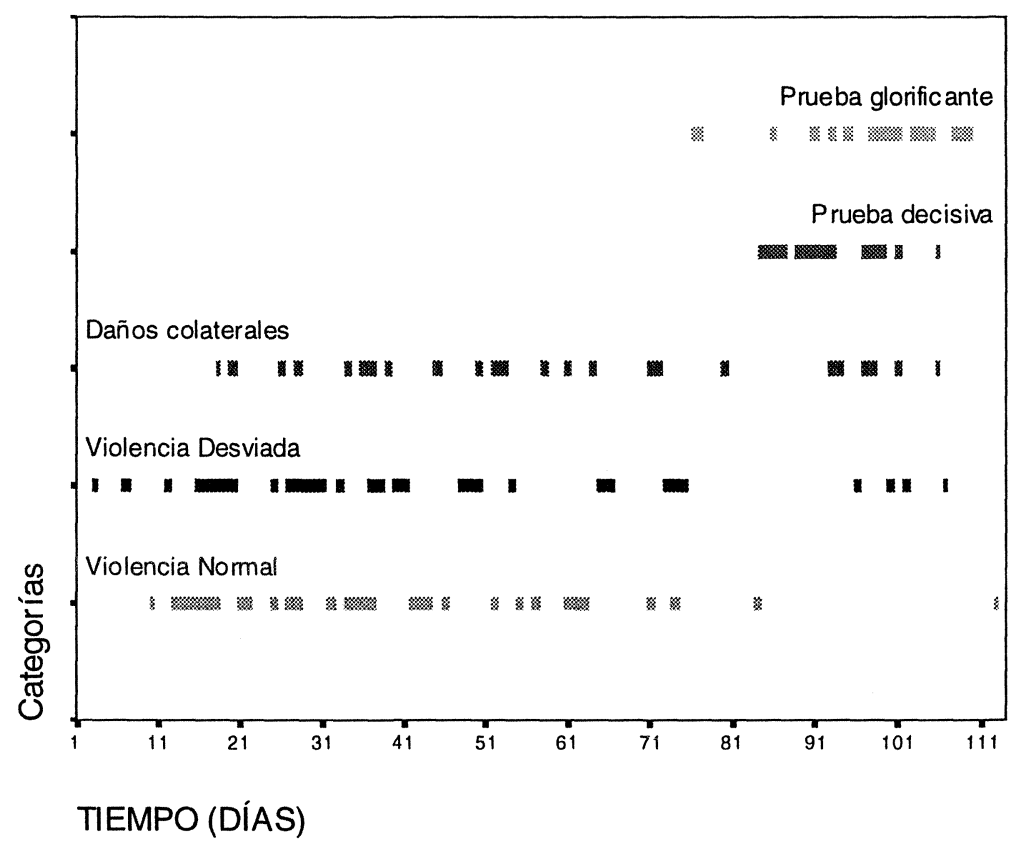

Tabla 1.

Tipos de violencia representada, frecuencia.

\begin{tabular}{lcc}
\hline Tipo de violencia & $\begin{array}{c}\mathrm{N}^{\mathbf{0}} \text { de días } \\
\text { con cobertura }^{13}\end{array}$ & $\begin{array}{c}\% \\
\text { sobre el total }\end{array}$ \\
\hline Violencia del oponente contra el objeto (violencia desviada) & 32 & 28,1 \\
Violencia del sujeto contra el oponente (violencia normal) & 31 & 27,2 \\
Violencia del oponente contra el sujeto (violencia desviada) & 2 & 1,8 \\
Violencia del sujeto sobre el objeto (daños colaterales y & 24 & 21,1 \\
desatención de refugiados) & 24 \\
\hline
\end{tabular}

${ }^{13}$ El resultado del sumatorio de los porcentajes no es 100 debido a la no presencia de violencia en los titulares de todas las fechas. 
(contrato). Observando la distribución temporal se pueden detectar ciclos entre las pérdidas (daños colaterales y violencia desviada) y ganancias de competencia (violencia normal).

En cuanto a los tipos de violencia representada llama la atención la ausencia de la relación entre violencia del oponente sobre el sujeto OTAN. Solamente dos noticias: derribo o caída de un avión espía norteamericano y captura de tres soldados de la misma nacionalidad.

\section{Formas de expresión de la violencia normal y la violencia desviada}

Por otro lado, se detecta en la secuencia dos formas diferentes de expresar lo que podríamos llamar historias paralelas: la de la violencia desviada y la de la violencia normal. Mientras las crónicas de los bombardeos son narradas predominantemente bajo la forma textual, las de los refugiados son expresadas mediante la imagen. Son dos formas de expresión donde la imagen - denotativa y analógica, frente al texto digitalizado- es lo real literal, ya que no media ninguna transformación, ni ningún código (Barthes, 1964). Su «efecto de realidad» consiste en la expulsión del significado y el vínculo directo entre el significante (lo expresado) y el referente (lo real). Sin embargo, sus indudables propiedades connotativas son más difíciles de descifrar, teniendo que acudir a lo histórico cultural (al «saber» del receptor) para acceder al código de la connotación: es probable que una buena foto periodística (y todas lo son puesto que están seleccionadas) juegue con el saber supuesto de sus lectores, eligiendo los clichés que contienen la mayor cantidad posible de informaciones de este tipo, para euforizar la lectura. No obstante, siguiendo a Barthes, son las fotografías de imágenes «traumáticas» las más cercanas a la pura denotación, a lo genuinamente objetivo y neutro. Anclada pues la realidad en la razón de ser de la guerra (la ayuda a la población albanokosovar), bajo la forma expresiva de las imágenes traumáticas, el resto de las acciones que rodean el conflicto son expresadas mediante texto, con un mayor poder connotativo y con una disposición de subordinación con respecto a la imagen. Realmente es la aspiración máxima del periodismo: el servir la realidad objetiva de manera neutra ${ }^{14}$.

\footnotetext{
${ }^{14}$ Otro recurso de la objetividad es la mención de la cifra. Puestos a analizar narrativamente la cobertura, podemos observar algunos ejemplos extraidos de la muestra de cómo sobre la imagen gráfica se puede detectar también la secuencia: salida misil desde el buque (día 25 de marzo), instantánea de una explosión sobre un objetivo alcanzado (día 26 de marzo); despedida antes de la partida de una soldado española ( 22 abril); desembarco en la llegada a Albania (27 de abril); anuncio procesamiento de Milosevic como criminal de guerra por parte del Tribunal de la Haya ( 27 de mayo) y al día siguiente fotografía de Milosevic con el gesto fascista del brazo extendido ( 28 de mayo); fotografía del fracaso negociación (14 abril), Ivanov y Albraight separados y con gesto
} 
Un dato más sobre la capacidad de expresión icónica, en este caso bajo el recurso retórico de la paradoja. Llama poderosamente la atención que en toda muestra solamente aparezca una noticia sobre movimientos de protesta de la sociedad civil de las naciones aliadas contra la guerra. Esa única noticia muestra la «violencia» de los pacifistas: se trata de la agresión que una facción de los verdes alemanes dirigió contra el ministro de este partido en el gobierno alemán (la imagen muestra al ministro sentado nada más recibir el impacto de un objeto).

\section{APROXIMACIÓN PARADIGMÁTICA}

\section{Análisis semiótico}

En el análisis de la cobertura se detecta el armazón narrativo del texto a partir de un conjunto de oposiciones binarias que se articulan principalmente desde una perspectiva axiológica (la oposición entre el bien y el mal), aunque también algunas de ellas indican movimiento (fuera-dentro; aire-tierra, salida-retorno, creación de carencia-liquidación de carencia). En el análisis del texto aparecen las siguientes oposiciones binarias:

\begin{tabular}{ll}
\hline Sujeto & Oponente \\
\hline Retorno (refugiados) & Salida (refugiados) \\
Liquidación de la carencia & Creación de carencia \\
Consecución de acuerdos & Ruptura de acuerdos \\
Democracia & Dictadura \\
Bien & Mal \\
Aire & Tierra \\
Desarrollo tecnológico & Atraso tecnológico \\
Exterior & Interior \\
Abierto & Cerrado \\
Alianza & Aislamiento \\
Pluralismo & Monolitismo \\
Grupo & Individuo \\
Flexibilidad & Obstinación \\
Identidad & Alienación \\
Pluralismo & Stalinismo \\
Paz & Guerra \\
\hline
\end{tabular}

amenazante del representante ruso y fotografía del acuerdo (sentados en actitud relajada y estrechándose la mano) (7 de mayo). 
Otras oposiciones aparecen entre el sujeto principal (EE.UU.) y sus ayudantes (en este caso la UE): fuerza y determinación vs debilidad e indecisión. O entre serbios y albaneses en Kosovo, muy importante para observar la diferente valoración mediática de la violencia: crimen vs venganza.

\section{Análisis de contenido}

Obviamente, la caracterización de los personajes según el esquema narrativo apunta hacia un desequilibrio de orden moral (héroe, villano) que también se puede mostrar desde el punto de vista cuantitativo. Mostramos, a continuación, algunos resultados del análisis de contenido para dar muestra del desequilibrio.

a) Personificación. Se conoce la tendencia a la personificación (mostrar los acontecimientos e incluso las estructuras como consecuencia de las acciones de unos cuantos sujetos) en la forma de presentar las noticias. No obstante, en el objeto de estudio se observa una mayor personificación del lado yugoslavo frente a su oponente.

Tabla 2.

Designación del oponente

\begin{tabular}{lcc}
\hline Designación & Frecuencia & Porcentaje \\
\hline Serbios/Serbia & 43 & 34,4 \\
Yugoslavia & 20 & 16,0 \\
Belgrado & 16 & 12,8 \\
Milosevic & 46 & 36,8 \\
Total & 125 & 100,0 \\
\hline
\end{tabular}

Tabla 3.

Designación del sujeto

\begin{tabular}{lrr}
\hline Designación & Frecuencia & Porcentaje \\
\hline Solana & 10 & 7,1 \\
Aliados & 26 & 18,6 \\
OTAN & 64 & 45,7 \\
EE.UU. & 9 & 6,4 \\
Clinton & 9 & 6,4 \\
Clark & 2 & 1,4 \\
Alemania & 3 & 2,1 \\
Francia & 1 & 0,7 \\
Reino Unido/Inglaterra & 2 & 1,4 \\
Italia & 2 & 1,4 \\
España & 12 & 8,6 \\
Total & 140 & 100,0 \\
\hline
\end{tabular}


Tabla 4.

Designación del objeto

\begin{tabular}{lcc}
\hline Designación & Frecuencia & Porcentaje \\
\hline Refugiados & 30 & 25,6 \\
Kosovares & 67 & 57,2 \\
Albaneses & 11 & 9,4 \\
Rugova & 3 & 2,5 \\
ELK/Guerrilla & 6 & 5,1 \\
Total & 117 & 100,0 \\
\hline
\end{tabular}

Contrasta con la designación como grupo de la otra parte: por las siglas de la organización OTAN o por los términos «aliados», alianza, etc... Clinton es el líder aliado no español que con más frecuencia aparece (un 5,6\% de las noticias). Destaca, no obstante, la presencia frecuente de un líder español (Solana, en su papel de secretario general de la OTAN) sobre el resto de líderes tanto locales como internacionales. Mientras la parte aliada forma una organización bien estructurada con diversas naciones actuando al unísono y con vicarios que actúan de negociadores, las decisiones políticas y estratégicas yugoslavas aparecen monopolizadas por un líder. La consecuencia es clara: se trata de contraponer democracia liberadora, con dictadura represora; pluralismo frente a monolitismo.

b) Además se muestra el recurso de la metonimia, en el sentido de designar una parte con relación al todo. Yugoslavia (objeto del bombardeo) es designada mayoritariamente como Serbia. Los habitantes albaneses de Kosovo (objetivo de la acción, su protección) son designados aludiendo a su condición de víctimas («refugiados») o como la totalidad, «kosovares» (sin hacer distinción entre albanokosovares y serbo-kosovares).

\section{CONCLUSIONES}

El descubrir sobre la secuencia discontinua de lo inesperado - la noticiauna tendencia a la dramatización y a la presentación de los hechos como una trama narrativa con héroes, villanos, pruebas y sanciones, no significa que podamos afirmar de manera definitiva que los acontecimientos no hayan tenido lugar o que se haya distorsionado la información. Para incluir los resultados de este estudio dentro del debate clásico relativo al papel de los medios de comunicación (entre manipulación deliberada y distorsión inconsciente) se han de tener en cuenta algunas consideraciones. 
En primer lugar, la estructura narrativa detectada no implica necesariamente que los hechos hayan sido inventados, ni tampoco que esta estructura haya sido premeditada (una orientación del texto donde una vez formulado el inicio, el desarrollo y la conclusión, los hechos sean presentados de una determinada forma). Puede ser que ciertas estructuras socioculturales impulsen a los productores de las noticias a seleccionar y presentar de una determinada forma este tipo de acontecimientos. Sobre este punto es esencial observar los diferentes estudios que hablan de las estructuras organizacionales, rutinas periodísticas y socialización de los periodistas (Bennett, 1983; Tuchman, 1983 Shoemaker, 1987; Rodrigo Alsina 1989).

En segundo lugar, de la misma forma que las pautas culturales actúan sobre los periodistas, la audiencia, según estos patrones, está acostumbrada a recibir las noticias como si fueran relatos. La audiencia detecta claramente la secuencia y crea unas expectativas sobre cómo se van a desarrollar los hechos (Cerulo, 1998). A partir de esta contingencia productores-audiencia, la estructura narrativa toma forma sobre el producto.

En tercer lugar, y aunque los anteriores puntos señalan una acción no consciente, no se ha de dejar de lado lo que podemos llamar control de la información. Para este nuevo elemento de filtro militar (Kellner 1992; Thomson 1998; también en Stevenson, 1997), la estructura narrativa y sus efectos ideológicos sobre las audiencias tienen una importancia transcendental, sobre todo cuando la existencia de un público acrítico resulta cómodo para las campañas militares. Los antecedentes en experiencias pasadas muestran a un poder político en constante alerta ante una opinión pública cada vez más crítica, sobre todo a partir de los años 60 y 70 (Chomsky y Ramonet, 1996).

Ciertamente, por razones teóricas y metodológicas, este análisis que aquí se ha presentado deja de lado el referente, es decir, la realidad sobre la que se basa el conjunto de informaciones. En primer lugar, porque la experiencia dice que en los conflictos bélicos el control sobre la información y las estrategias de las fuentes de información hacen que la «objetividad» periodística quede bastante deteriorada (Chomsky y Herman 1990, Chomsky 1996; Chomsky y Ramonet, 1996; Ramonet, 1992; Kellner, 1992; Thompson, 1998), sobre todo a partir de la experiencia de Vietnam. Pero también obedece a una precaución de orden metodológico al no disponer de datos extra-textuales o extra-mediáticos con los que contrastar las informaciones que forman el corpus textual.

No obstante, aunque existen ciertas coincidencias con otro conflictos bélicos en cuanto a la presencia en la cobertura mediática de ciertas formas de hiperrealidad que impiden el conocimiento inmediato de la verdad sobre los hechos, este trabajo no pretende decir que la guerra en Kosovo «no haya existido» a la manera de Baudrillard durante la guerra del Golfo (interesante la crítica que hace Norris, 1997, a Baudrillard 1991). Todo lo contrario, si en este trabajo se observa la coincidencia de la estructura de la cobertura del conflicto con la es- 
tructura del mito o del «cuento maravilloso», es para que sirva de formulación de hipótesis para indagar sobre las verdades y falsedades de la guerra, una vez haya acabado el conflicto y el rigor científico pueda actuar sobre el terreno. Esa futura tarea permitiría seguir abundando en el esquema producido por Golding y Elliott (1979) en torno a los efectos a corto y largo plazo y las dos perspectivas a partir de las cuales estudiar el fenómeno: la del periodista que se preocupa por la manipulación consciente de la información, y la del sociólogo que se interesa más por la conformación de la ideología (algo no deliberado). Solamente la rigurosidad (en cuanto a la confirmación de que los hechos se han producido) y un cierto distanciamiento crítico pueden ayudar a esclarecer la posible manipulación consciente.

Para terminar, creemos que es conveniente preguntarse si realmente ha concluido la guerra en Kosovo. Si atendemos a la cobertura mediática, se podría contéstar que sí. Esto queda patente en la paulatina reducción de noticias tras la firma de los acuerdos y la progresiva desaparición del conflicto en las primeras páginas del diario. No obstante, si el contrato consistía en la eliminación de Milosevic, éste se ha llevado a cabo de manera simbólica, pero no real. Según Wallerstein (1999) el acuerdo que puso fin a los bombardeos dejó las cosas tal y como estaban anteriormente a las negociaciones de Ramboulliet; negociaciones de las cuales no se ofreció la suficiente información respecto a las cláusulas que indicaban el despliegue de tropas por todo el territorio yugoslavo, y no solamente en la provincia de Kosovo (Fernández Buey, 1999). La estructura narrativa de las noticias ha hecho que la finalización de la guerra (performance y sanción) se haya producido de manera simbólica (se constata en unas cuantas noticias de portada: liberación, entrada de tropas, Solana aclamado por la población kosovar, anuncio del procesamiento del líder yugoslavo por el Tribunal de la Haya), pero no real. Se detecta, por tanto, una difusa definición del contrato (¿eliminación del régimen yugoslavo o regreso de los refugiados?) que deja nuevas vías para próximas intervenciones militares y que tiene reminiscencias con el conflicto del Golfo. Así, se pueden vislumbrar nuevos pretextos para las intervenciones militares, como pueden ser el apoyo a la oposición yugoslava o la captura de Milosevic para su procesamiento. En cualquier caso sabemos que ninguna justificación será efectiva sin el componente humanitario, necesario para atenuar el papel de una opinión pública alerta y crítica con la violencia.

\section{BIBLIOGRAFÍA}

ALAMINOS, A. (1999), Análisis de discurso, Alicante, Editorial Club Universitario.

ARIAS, M.A. (1986), «Una aplicación del modelo dialéctico: el proceso de mediación cultural en la prensa escrita», Revista Española de Investigaciones Sociológicas, 33, pp. 175-186.

BARTHES, R. (1964), «Elements de sémiologie», Communications, 4, París. 
BAUDRILLARD, J. (1991), La guerra del Golfo no ha tenido lugar, Barcelona, Anagrama.

CAREY, J.W. (1992), Communication as culture. Essays on media and society, New York, Routledge.

CERULO, K.A. (1998), Deciphering Violence. The Cognitive Structure of Right and Wrong, New York, Routledge.

CHOMSKY, N. (1996), El nuevo orden mundial (y el viejo), Barcelona, Crítica.

CHOMSKY, N. y E.S. HERMAN (1990), Los guardianes de la libertad, Barcelona, Crítica.

CHOMSKY, N. y I. RAMONET (1996), Cómo nos venden la moto, Barcelona, Icaria.

FERNÁNDEZ BUEY, F. (1999), «¿Qué decían los acuerdos de Rambouillet?, El País, 10 de mayo.

FISAS, V. (1988), Cultura de paz y gestión de conflictos, Barcelona, Icaria.

FISKE, J. y J. HARTLEY (1978), Reading Television, London, Methuen.

FISKE, S.T. y S.E. TAYLOR (1991), Social Cognition, New York, McGraw-Hill.

FLOCH, J.M. (1993), Semiótica, marketing y comunicación, Paidós, Barcelona.

GAltung, J. (1995), Peace by Peaceful Means. Peace and Conflict, Development and Civilization, Londres, PRIO y SAGE.

GALTUNG, J. y M.H. RUGE (1965), "The Structure of Foreign News", Journal of Peace Research, $n^{0} 11$.

GLASGOW UNIVERSITY MEDIA GROUP (1982), Really Bad News, London, Writers and Readers.

(1985) Peace and War News, Milton Keynes, Open University Press.

GOLDING, P. y P. ELLIOTT (1979), Making the News, London, Longman.

GONZÁLEZ RÍO, M.J. (1997), Metodología de la Investigación Social. Técnicas de recolección de datos, Alicante, Aguaclara.

GREIMAS, A.J. (1980), «Las adquisiciones y los proyectos», estudio preliminar en J. Courtés, Introducción a la semiótica narrativa y discursiva, Buenos Aires, Hachette.

HANSE, A., S. COTTLE, R. NEGRINE y C. NEWBOLD (1998), Mass Communication Research Methods, MacMillan Press, London.

HEDMAN, L. (1981), "International Information in Daily Newspapers", en K.E. Rosengren (ed.) Advances in Content Analysis, Beverly Hills, Ca. SAGE. 197-214.

HURWITZ, J. y M. PERFFLEY (1990), "Public Images of the Soviet Union", Journal of Politics, 52,1 , pag. 3-28. 
IBÁÑEZ, J. (1994), "El País: un dispositivo de producción de realidad", Sociología de la vida cotidiana, Madrid, Siglo XXI. (pp. 201-207)

IMBERT, G. y J. VIDAL-BENEYTO (coord.) (1991), El País o la referencia dominante, Barcelona, Mitre.

KATZ, E. (1992), "The End of Journalism? Notes on Watching the War", Journal of Communication $42(3), 5-13$.

KELLNER, D. (1992) The Persian Gulf TV War, Boulder, Co., Westview Press.

LÉVI-STRAUSS, C. (1961), Antropología estructural, Buenos Aires, Eudeba.

MARTÍN SERRANO, M. (1986), La producción social de la comunicación, Madrid, Alianza.

McLUHAN, M. (1989), La comprensión de los medios como las extensiones del hombre, México, Diana.

NORRIS, C. (1997), Teoría acrítica. Postmodernismo, intelectuales y la Guerra del Golfo, Madrid, Cátedra.

PENALVA, C., A. ALAMINOS, C. ZUELL y P. MOHLER (1999), Textpack. Manual de usuario. Mannheim, ZUMA.

PROPP, V. (1977), Morfología del cuento, Madrid, Fundamentos.

RAMONET, I. (1992) «Mass-media y política internacional en tiempo de guerra», Treballs de comunicació, $\mathrm{n}^{\circ} 3$, pág. 125-140.

RODRIGO ALSINA, M. (1989), La construcción de la noticia, Barcelona, Paidós.

ROSENBLUM, M. (1979), Coups and Earthquakes:Reporting the World for America, Nueva York, Harper and Row.

ROSENGREN, K.E. (1970), "International News: Time and Type of Report" en H.D. Fischer y J.C. Merrill (eds.), International Communication, Media, Channels, Functions, Nueva York, Communication Juty Books.

SARTORI, G. (1998), Homo videns. La sociedad teledirigida, Madrid, Taurus.

SCHUDSON, M. (1989) "How Culture Works. Perspectives from media studies on the efficacy of symbols", Theory and Society, 8, 2, pp. 153-180.

SHOEMAKER, P. (1987), "Building a Theory of News Content: A Syntesis of Current Approaches", Journalism Monograph, 103.

TORTOSA, J.M. (1996), El patio de mi casa: El nacionalismo dentro de los límites de la mera razón, Barcelona, Icaria. 
TUCHMAN, G. (1983), La producción de la noticia. Estudio sobre la construcción de la realidad. Barcelona, Gustavo Gili (1978).

VAN DIJK,T.A. (1990), La noticia como discurso. Comprensión, estructura y producción de la información, Paidós, Barcelona, 1990, pp. 201-219.

WALLERSTEIN, I. (1999) «The Clinton-Milosevich Chess Match» Comments No. 19, July 1 , http://fbc.binghamton.edu/19-!en.htm.

ABSTRACT. This work is an approach to the latent structure of the mediatic coverage in Spain of the intervention of NATO in Yugoslavia in the days in which the bombing of the country took place after the new outbreak of the conflict in the province of Kosovo. The period we study starts from few days before the beginning of the bombings to the $31^{\text {st }}$ of July 1999. The study is based on the conjunction of two methods of textual analyses employed on a textual corpus formed by the news about the conflict appeared in the cover of the newspaper El País. On the one hand, the semiotic analysis is used to observe the narrative sequence of the events and, on the other hand, the content analysis examines the designation names and attributions made on the actors implied in the conflict, as well as their presence throughout the sequence.

The analysis of the data shows a tendency of the media to display the events within a narrative structure in which the actors can be determined. In the plot of story also appears actions and transformations (as if they were trials of competence), performances, as well as the contractual and sanctioning dispositions of the narrative itinerary of the story heroe.

E-mail: ma.mateo@ua.es clemente.penalva@ua.es 